\title{
Recuperação de gotejadores obstruídos devido à utilização de águas ferruginosas ${ }^{1}$
}

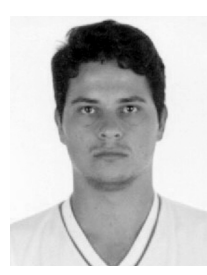

Gustavo H. S. Vieira ${ }^{2}$, Everardo C. Mantovani ${ }^{3}$, José G. F. da Silva ${ }^{4}$, Márcio M. Ramos ${ }^{5}$ \& Cláudio M. Silva ${ }^{6}$

\footnotetext{
${ }^{1}$ Extraído de Dissertação de Mestrado do primeiro autor, apresentada á UFV

2 CEFET. CP 97, CEP 39480-000, Januária, MG. Fone: (38) 3621-1100. E-mail: ghaddad@comnt.com.br (Foto)

${ }^{3}$ DEA/UFV. CEP 36571-000, Viçosa, MG. Fone: (31) 3899-1913. E-mail: everardo@ufv.br

${ }^{4}$ INCAPER. CP 62, CEP 29900-970, Linhares, ES. Fone: (27) 3371-0377. E-mail: jgeraldo@incaper.es.gov.br

${ }^{5}$ DEA/UFV. Fone: (31) 3899-1914. E-mail: mmramos@ufv.br

${ }^{6}$ DEF/UFV. Fone: (31) 3899-2083. E-mail: mudado@ufv.br
}

Protocolo 49 - 25/3/2003 - Aprovado em 9/1/2004

\begin{abstract}
Resumo: Desenvolveu-se este trabalho com o objetivo de se avaliar a eficiência da utilização de ácido fosfórico, de hipoclorito de sódio e de um produto comercial, além do impacto mecânico na desobstrução de gotejadores entupidos, devido à utilização de águas com elevado teor de ferro. O trabalho foi realizado na Fazenda Vista Alegre, localizada em Jaboticatubas, MG. Um sistema de irrigação por gotejamento foi adaptado para realização dos testes com oito tratamentos, sendo sete com aplicação de produtos químicos e um com impacto mecânico. Para os tratamentos químicos, utilizaram-se: o ácido fosfórico com pH 2 e pH 3; o hipoclorito de sódio com as dosagens de 100, 50 e $25 \mathrm{mg} \mathrm{L}^{-1}$ de cloro; e Reciclean com as dosagens de 50 e $25 \mathrm{mg} \mathrm{L}^{-1}$. Diante dos resultados obtidos, conclui-se: o tratamento com ácido fosfórico em $\mathrm{pH} 2$ forneceu o melhor resultado quanto ao aumento da uniformidade de aplicação de água pelo sistema, apresentando o maior aumento nos valores de coeficiente de uniformidade de distribuição (CUD) e coeficiente de uniformidade de Christiansen (CUC); entretanto, com custo elevado. O tratamento com $25 \mathrm{mg} \mathrm{L}^{-1}$ de cloro apresentou a melhor relação benefício/custo, sendo o mais econômico e o segundo melhor quanto à melhoria da uniformidade de irrigação do sistema. O impacto mecânico é uma alternativa para recuperação de sistemas de irrigação por gotejamento em geral, com destaque para sistemas de cultivos orgânicos.
\end{abstract}

Palavras-chave: irrigação por gotejamento, desentupimento, uniformidade de aplicação

\section{Recovery of drippers clogged by use of water high in iron content}

\begin{abstract}
A study was carried out (Reciclean) to evaluate the efficiency of using the phosphoric acid, sodium hypochlorite, a commercial product and mechanical impact for cleaning the drippers in which the clogging was due to the presence of high iron content in water. The experiment was set up in the Vista Alegre Farm, located in Jaboticatubas County - Minas Gerais State. A drip irrigation system was adopted for the accomplishment of the tests. Eight treatments were tested, of which, seven with application of chemical products and one with mechanical impact. In accomplishing the chemical treatments, the phosphoric acid was used at $\mathrm{pH} 2$ and 3, sodium hypochlorite at 100, 50 and $25 \mathrm{mg} \mathrm{L}^{-1}$ chlorine and Reciclean at 50 and $25 \mathrm{mg} \mathrm{L}^{-1}$. According to the results, the following conclusions were drawn: the treatment using the phosphoric acid at $\mathrm{pH} 2$ provided the best results, when evaluating the improvement of uniformity in the irrigation system, since it showed the highest increase in the values of uniformity coefficients (CUD and CUC); however, it is an expensive treatment. The treatment with $25 \mathrm{mg} \mathrm{L}^{-1}$ chlorine presented the best benefit/cost relation, since it showed to be the cheapest besides being the second best in improving the uniformity of the irrigation system. The mechanical impact is a good alternative to recover the drip irrigation systems, principally under organic farming.
\end{abstract}

Key words: drip irrigation, unclogging, water application uniformity

\section{INTRODUÇÃO}

Um dos aspectos mais importantes a serem observados no manejo da irrigação, é a uniformidade de distribuição de água pelo sistema. Na irrigação localizada, vários fatores podem comprometer esta uniformidade, tais como a desuniformidade dos emissores, devido a processos de fabricação, o dimensionamento inadequado do sistema, bem como o entupimento dos emissores causado pelas partículas minerais ou orgânicas presentes na água. No sistema por gotejamento, a qualidade 
da água deve ser observada, pois ela escoa por orifícios de pequeno diâmetro, podendo causar obstrução devido à deposição dos materiais que carrega em suspensão. O entupimento de emissores é um grave problema associado ao gotejamento, visto que dificulta a operação de sistemas de irrigação, é de difícil detecção e a limpeza ou substituição dos emissores entupidos é onerosa.

O entupimento de emissores pode resultar de causas físicas (areia, silte e argila), biológicas (bactérias e algas) ou química (deposição mineral) (Pitts et al., 1990). Segundo Ravina et al. (1992), a determinação da causa exata do entupimento de emissores pode ser complexa, vez que vários agentes na água podem interagir entre si, agravando o problema.

Segundo Martinko et al. (1997), o entupimento ocorre em razão da ação bacteriana associada ao ferro que, ao ser oxidado da forma ferrosa $\left(\mathrm{Fe}^{2+}\right)$ para a forma férrica $\left(\mathrm{Fe}^{3+}\right)$, forma precipitados de hidróxido férrico $\left(\mathrm{Fe}(\mathrm{OH})_{3}\right)$ muito insolúveis em água.

Na região Sudeste do Brasil se encontram, com freqüência, águas que apresentam elevados teores de ferro total, elemento este que pode provocar sérios problemas de entupimento, sobretudo quando presente em forma reduzida, podendo precipitar-se no interior das tubulações quando oxidado favorecendo, ainda, o desenvolvimento de ferrobactérias (Cordeiro, 2002).

Para o tratamento de recuperação dos emissores existem produtos que removem o limo aderido às paredes das tubulações e gotejadores deixando, assim, a passagem de água novamente livre.

Segundo Pitts et al. (1990), o ácido pode ser usado para abaixar o $\mathrm{pH}$ da água e reduzir o potencial de precipitação química. Ácido sulfúrico $\left(\mathrm{H}_{2} \mathrm{SO}_{4}\right)$, clorídrico $(\mathrm{HCl})$, fosfórico $\left(\mathrm{H}_{3} \mathrm{PO}_{4}\right)$ e nítrico $\left(\mathrm{HNO}_{3}\right)$ são usados para este propósito.

Diversos produtos podem ser utilizados neste tratamento de recuperação. O ácido fosfórico que, ao adicionar íons hidrogênio altamente reativos à solução, dissocia os compostos insolúveis, formando compostos solúveis que podem ser removidos do sistema de irrigação. $\mathrm{O}$ hipoclorito que, devido ao seu poder oxidante e biocida, pode remover as deposições, por meio da oxidação da matéria orgânica e morte das ferrobactérias. O peróxido de hidrogênio atua como forte oxidante, removendo as partículas aderidas no interior das tubulações e gotejadores.

Portanto, o presente trabalho teve como objetivos:

- avaliar a desobstrução de gotejadores, utilizando-se diferentes concentrações de hipoclorito de sódio ( $\mathrm{NaClO})$, de ácido fosfórico $\left(\mathrm{H}_{3} \mathrm{PO}_{4}\right)$, um produto comercial (Reciclean) e um tratamento com impacto mecânico;

- determinar a concentração do produto mais eficiente no processo de desobstrução;

- fazer análise de custo das aplicações.

\section{MATERIAL E MÉTODOS}

O experimento foi realizado na Fazenda Vista Alegre, localizada no município de Jaboticatubas, MG. A área é irrigada por um sistema de irrigação por gotejamento marca Plastro, emissores Katif, com vazão nominal de $2,3 \mathrm{~L} \mathrm{~h}^{-1}$, autocompen- santes, espaçados $0,8 \mathrm{~m}$ entre si, em tubos de polietileno de baixa densidade (PEBD) com $16 \mathrm{~mm}$ de diâmetro em linhas de $90 \mathrm{~m}$ de comprimento, com cerca de oito anos de funcionamento.

Uma análise preliminar da água de irrigação indicou teor de ferro total igual a $0,7 \mathrm{mg} \mathrm{L}^{-1}$, o que a classifica como de moderado poder de entupimento, segundo Bucks \& Nakayama (1980).

Constataram-se problemas de entupimento dos emissores, além da formação de mucilagem nas paredes internas das tubulações, o que se pode observar nas Figuras 1 e 2 .

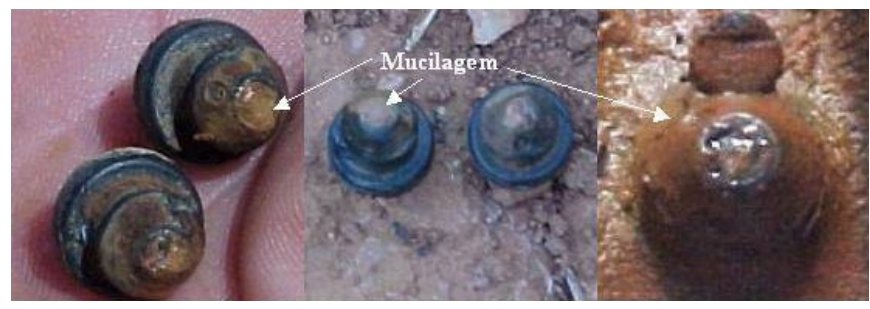

Figura 1. Detalhe mostrando a formação de mucilagem na entrada dos gotejadores e nas paredes internas das tubulações

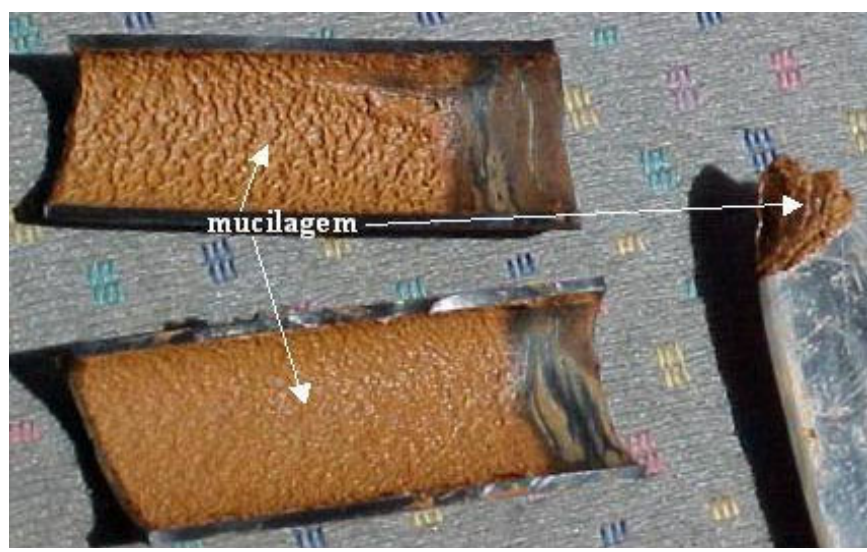

Figura 2. Mucilagem formada nas paredes internas dos tubos de polietileno de baixa densidade com detalhe de uma raspagem feita com canivete em um segmento do tubo

Para realização do experimento foi necessário fazer-se uma alteração no sistema de irrigação. Um tubo de polietileno com $25 \mathrm{~mm}$ de diâmetro foi instalado perpendicularmente às linhas laterais e paralelo à linha de derivação. Este tubo foi conectado ao cavalete de entrada de setor, para conduzir a água até as linhas laterais selecionadas, que foram cortadas e conectadas ao mesmo. $\mathrm{O}$ experimento foi dividido em parcelas com quatro linhas laterais consecutivas de, aproximadamente, $90 \mathrm{~m} \mathrm{de}$ comprimento. $\mathrm{Na}$ entrada de cada parcela foi colocada uma válvula de gaveta para controlar a pressão, devido às condições topográficas do local (Figura 3). Esta montagem permitiu que os tratamentos fossem isolados, a fim de facilitar a entrada de água somente nas linhas laterais desejadas.

Utilizou-se o delineamento experimental em blocos casualizados, com três repetições, cada uma constando de quatro linhas laterais consecutivas; também testaram-se três produtos químicos, dois com duas concentrações, um com três concentrações e um tratamento físico de impacto mecânico na recuperação de gotejadores obstruídos, totalizando oito tratamentos (Tabela 1). 


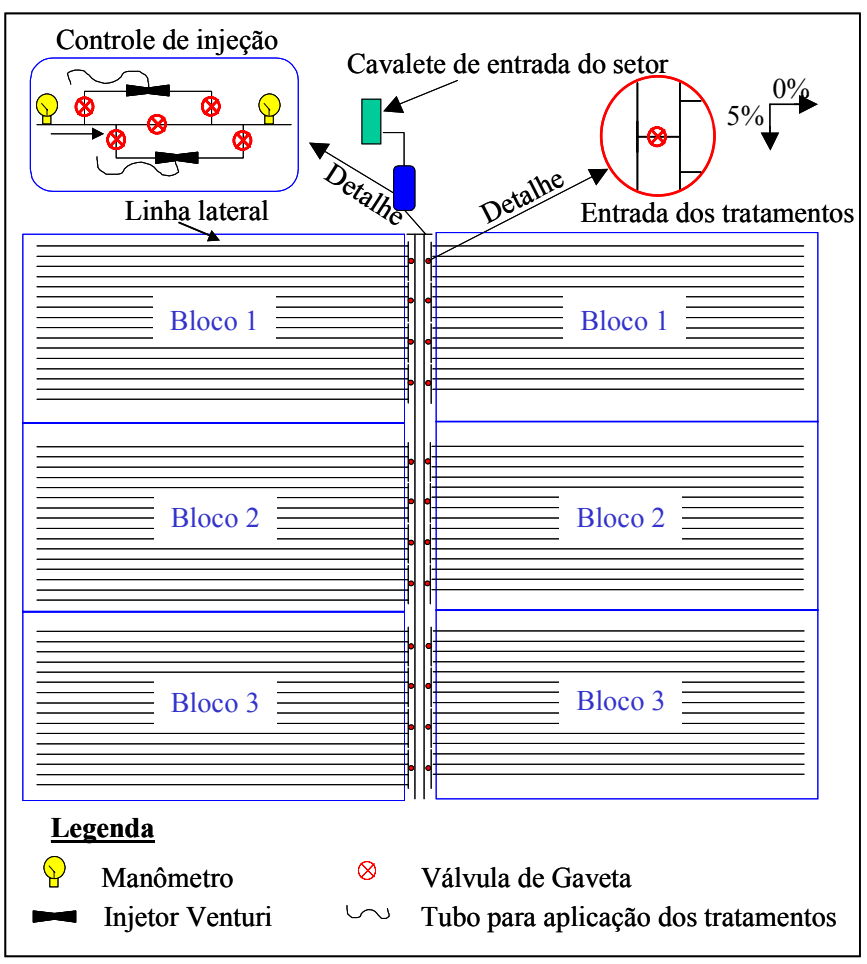

Figura 3. Representação esquemática da montagem feita para realização do experimento

Tabela 1. Especificação dos tratamentos aplicados

\begin{tabular}{cccc}
\hline Trat. & Produto & Concentração & Observação \\
\hline T1 & Ácido & $\mathrm{pH} 2$ & Recomendação \\
T2 & Fosfórico(85\%) & $\mathrm{pH} \mathrm{3}$ & Acima da recomendação \\
T3 & Hipoclorito de Sódio & $100 \mathrm{mg} \mathrm{L}^{-1}$ & $200 \%$ da recomendação \\
T4 & $(12 \%)+$ Ácido & $50 \mathrm{mg} \mathrm{L}^{-1}$ & Recomendação \\
T5 & & $25 \mathrm{mg} \mathrm{L}^{-1}$ & $50 \%$ da recomendação \\
T6 & ------ & ----- & Impacto mecânico \\
T7 & Reciclean & $50 \mathrm{mg} \mathrm{L}^{-1}$ & $200 \%$ da recomendação \\
T8 & & $25 \mathrm{mg} \mathrm{L}^{-1}$ & Recomendação \\
\hline
\end{tabular}

Nos tratamentos com ácido fosfórico foram testados dois níveis de $\mathrm{pH}$ diferentes, sendo que no Tratamento T1 utilizouse um $\mathrm{pH}$ da água igual a 2 , conforme recomendado na literatura e, no Tratamento T2, o pH igual a 3, para testar o efeito de uma menor concentração do ácido. Para determinação da quantidade de ácido a ser adicionada à água de irrigação, fez-se uma titulação. Durante as aplicações foram coletadas amostras de água nos gotejadores, para confirmação do $\mathrm{pH}$ da solução.

Três tratamentos com hipoclorito, denominados T3, T4 e T5, foram realizados utilizando-se uma concentração de cloro ativo igual a 100,50 e $25 \mathrm{mg} \mathrm{L}^{-1}$, respectivamente. Nesses tratamentos usou-se o hipoclorito de sódio $(\mathrm{NaClO})$, que contém $12 \%$ de cloro livre, juntamente com ácido fosfórico $\left(\mathrm{H}_{3} \mathrm{PO}_{4}\right) 85 \%$, utilizado para abaixar o $\mathrm{pH}$ da solução, pois quando se adiciona o hipoclorito à água ocorre aumento no pH, o que não é desejado.

Foi feita uma titulação da água de irrigação com o ácido, para cada tratamento, enquanto o $\mathrm{pH}$ da água foi mantido em torno de 5 , de modo a permitir uma concentração maior de ácido hipocloroso na solução.
Durante as aplicações coletaram-se amostras de água nos gotejadores mais distantes do sistema de injeção e medidos o $\mathrm{pH}$ e o teor de cloro livre da solução; para isto, foram utilizados um medidor de $\mathrm{pH}$ e um kit da marca $\mathrm{HACH}$, o qual utiliza, como reagente, o D.P.D. ( $\mathrm{N}$ - dietil - $\mathrm{p}$ - fenil - diamina), que mede apenas o cloro livre.

O tratamento com impacto mecânico consistiu na aplicação de golpes com uma vareta metálica, sobre toda a extensão das mangueiras, a fim de desprender as incrustações das paredes internas das mangueiras e do interior dos gotejadores, as quais são eliminadas do sistema. Este procedimento se deu com o sistema ligado e os finais de linha abertos. O tempo gasto na operação foi cronometrado e utilizado para estimar o custo da mão-de-obra gasta no tratamento.

Reciclean é um produto comercial próprio para limpeza de sistemas de irrigação e é fabricado pela empresa Kemira; tratase de um produto de dois componentes: Reciclean W1, que contém $35 \%$ de peróxido de hidrogênio, e Reciclean W2, com $15 \%$ de ácido fórmico. Esses componentes são misturados na proporção de 1:1 em volume, $8 \mathrm{~h}$ antes da aplicação, para permitir a ocorrência da reação. Foram testadas duas concentrações, sendo elas 50 e $25 \mathrm{mg} \mathrm{L}^{-1}$, respectivamente aos tratamentos $\mathrm{T} 7 \mathrm{e}$ T8.

Os produtos químicos foram injetados na tubulação por meio de um sistema de controle de injeção, constituído de dois injetores Venturi, cinco válvulas de gaveta, dois manômetros e conexões. Foi necessária a instalação de dois injetores, pois no caso de aplicação de cloro deve-se aplicar o ácido separadamente, a fim de evitar possíveis reações químicas.

Antes da aplicação dos tratamentos realizou-se uma avaliação de todas as parcelas, de modo a permitir uma comparação dos resultados, com os valores iniciais de uniformidade.

O modo de aplicação foi semelhante em todos os tratamentos, fazendo-se três aplicações em cada um. Após a primeira avaliação, era feita a primeira aplicação, com duração de 10 min, enquanto a segunda e a terceira aplicações foram feitas com duração de $1 \mathrm{~h}$ cada uma. A aplicação de $10 \mathrm{~min}$ foi necessária para evitar que ocorresse o problema de desprendimento de partículas maiores e estas fossem parar dentro do gotejador, piorando ainda mais o problema de entupimento.

Terminada a aplicação, o sistema era imediatamente desligado e deixado em repouso por aproximadamente $12 \mathrm{~h}$, quando era feita a abertura dos finais de linha e novamente ligado o sistema para realizar a lavagem das tubulações, que eram fechadas assim que se constatava a saída de água limpa por pelo menos $2 \mathrm{~min}$, garantindo, assim, que todo o material desprendido fosse eliminado do sistema. Terminado o processo de limpeza, imediatamente era feita outra avaliação.

As avaliações foram realizadas seguindo-se a metodologia proposta por Keller \& Karmeli (1975), modificada por Denículi et al. (1980). Avaliaram-se 4 linhas laterais, ou seja, a primeira linha, as localizadas a 1/3, a 2/3 do início da parcela e a última. Em cada linha foram avaliados 8 gotejadores, isto é, o primeiro, os localizados a 1/7, 2/7, 3/7, 4/7, 5/7, 6/7 do início da linha lateral e o último, totalizando 32 gotejadores avaliados por setor. Os gotejadores foram marcados, de modo que sempre eram avaliados. 
Ao final das coletas (com duração de 3 min cada), os volumes foram medidos em uma proveta graduada, anotados em planilhas e calculada a vazão $\left(\mathrm{L} \mathrm{h}^{-1}\right)$. Com esses valores foram calculados o coeficiente de uniformidade de distribuição (CUD) (Keller \& Karmeli, 1975) e o coeficiente de uniformidade de Christiansen (CUC) (Bernardo, 1995) que são calculados pelas Eqs. 1 e 2.

$$
\mathrm{CUD}=100 \frac{\mathrm{q}_{25 \%}}{\mathrm{q}_{\mathrm{m}}}
$$

em que:

$\mathrm{q}_{25 \%}$ - média do menor quartil das vazões observadas, $\mathrm{em} \mathrm{L} \mathrm{h}^{-1}$

$\mathrm{q}_{\mathrm{m}}$ - vazão média dos gotejadores, em $\mathrm{L} \mathrm{h}^{-1}$

$$
\mathrm{CUC}=100\left(1-\frac{\sum_{\mathrm{i}=1}^{\mathrm{n}}\left|\mathrm{qi}-\mathrm{q}_{\mathrm{m}}\right|}{\mathrm{nq}_{\mathrm{m}}}\right)
$$

em que:

CUC - coeficiente de uniformidade de Christiansen, em \%

qi - vazão de cada gotejador, em $\mathrm{L} \mathrm{h}^{-1}$

$\mathrm{q}_{\mathrm{m}}$ - vazão média dos gotejadores, em $\mathrm{L} \mathrm{h}^{-1}$

n - número de observações

A fim de se selecionar o tratamento com a melhor relação benefício/custo, realizou-se uma análise de custo, para cujo cálculo se considerou o valor dos produtos químicos gastos nas aplicações, para o volume de um metro cúbico de água e um hectare, considerando-se a cultura do café. O volume de água tratada foi calculado estimando-se a vazão média dos gotejadores contidos na parcela (tratamento). Para o tratamento físico, considerou-se o custo por hectare, medindo-se o tempo gasto por pessoa, para a limpeza de cada linha lateral, extrapolando-se o valor para um hectare. Os preços dos produtos foram consultados junto aos fornecedores.

Para os tratamentos de T3 a T5, computaram-se os gastos com o hipoclorito e o ácido fosfórico. Para determinar o custo da mão-de-obra no tratamento T6, o tempo gasto na limpeza de uma linha lateral foi cronometrado considerando-se, ainda, o tempo gasto na abertura dos finais de linha e o tempo de espera para expulsão do material desprendido da mesma. Foi considerado um número de 28 linhas laterais por hectare, devido ao espaçamento de 3,5 m entre linhas. Considerou-se uma jornada de trabalho de $7 \mathrm{~h} \mathrm{~d}^{-1}$, em vinte dias por mês, conforme aquela adotada pela fazenda onde foi realizado o experimento.

Foram comparados os aumentos nos valores de CUD e CUC da última avaliação em relação à primeira, ou seja, subtraiuse o valor obtido na última avaliação pelo valor da primeira.

Foram levados em conta, ainda, os encargos sociais, como $13^{\circ}$ salário, férias, INSS e FGTS dos operadores de turno diurno, de acordo com os dados fornecidos pela administração da Fazenda Vista Alegre.
Todos os dados observados foram analisados pela análise de variância e comparados pelo teste de Tukey a $5 \%$ de probabilidade.

\section{RESULTADOS E DISCUSSÃO}

\section{Coeficiente de uniformidade de distribuição}

Para se avaliar os efeitos dos tratamentos na limpeza dos sistemas de irrigação, os valores de CUD foram classificados segundo a norma ASAE (1996). Na Figura 4 são apresentados os valores de CUD médio, antes e depois de cada aplicação dos tratamentos e sua classificação.

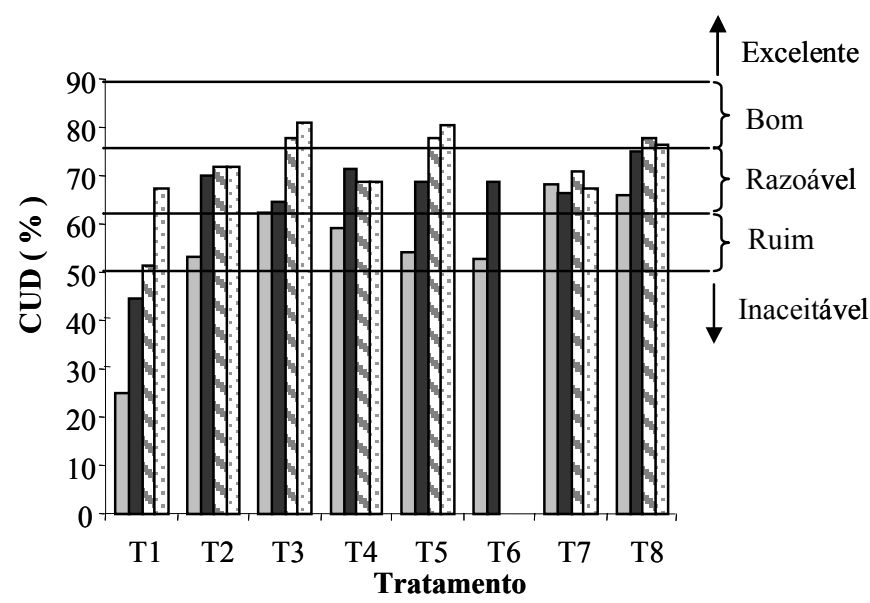

1 aval. $\square 2^{\mathrm{a}}$ aval. $\square 3^{\mathrm{a}}$ aval. $\square 4^{\mathrm{a}}$ aval.

Figura 4. Valores de coeficiente de uniformidade de distribuição (CUD) médio para os tratamentos e faixas de classificação quanto à norma ASAE EP 458 (1996)

Para o tratamento $\mathrm{T} 1$ observa-se que a uniformidade inicial (antes das aplicações) estava na faixa inaceitável, passando para ruim na terceira avaliação e razoável na quarta. Seria desejável que a uniformidade estivesse na faixa excelente ou, pelo menos, bom mas, mesmo assim, ocorreu aumento no valor de CUD, melhorando as condições de distribuição da água na lavoura, o que pode ser considerado um efeito positivo deste tratamento.

Os tratamentos T2, T4 e T6 passaram da faixa ruim para a razoável, mostrando também um efeito benéfico desses tratamentos. $\mathrm{O}$ tratamento $\mathrm{T} 5$ passou de ruim para bom, o que demonstra resultado desejável; os tratamentos T3 e T8 passaram da faixa razoável para bom, enquanto o tratamento T7 permaneceu na mesma faixa (razoável), mostrando, ainda, um ligeiro decréscimo do valor de CUD, cujo resultado evidencia que, em certos casos, pode ocorrer desprendimento de partículas aderidas à parede interna da tubulação, que se deslocarão para o interior dos gotejadores, piorando ainda mais o problema de entupimento.

Para comparar os efeitos dos tratamentos no aumento da uniformidade de distribuição, foram calculados os aumentos desses valores após a aplicação dos tratamentos em relação aos valores iniciais, antes das aplicações. A Tabela 2 apresenta os aumentos nos valores de CUD. 
Tabela 2. Aumento dos valores de coeficiente de uniformidade de distribuição (CUD) após aplicação dos tratamentos, em relação aos valores iniciais

\begin{tabular}{cc}
\hline Tratamento & Aumento do CUD* \\
T1 & $42,29 \mathrm{a}$ \\
T2 & $18,55 \mathrm{a} \mathrm{b}$ \\
T3 & $18,55 \mathrm{a} \mathrm{b}$ \\
T4 & $9,63 \mathrm{a} \mathrm{b}$ \\
T5 & $26,64 \mathrm{a} \mathrm{b}$ \\
T6 & $16,01 \mathrm{a} \mathrm{b}$ \\
T7 & $-0,65 \mathrm{~b}$ \\
T8 & $10,50 \mathrm{a} \mathrm{b}$ \\
\hline
\end{tabular}

* As médias seguidas por uma mesma letra não diferem estatisticamente pelo teste de Tukey, em nível de $5 \%$ de probabilidade

Os resultados foram analisados estatisticamente pelo teste de Tukey com $5 \%$ de probabilidade, observando-se que o tratamento T1 se diferencia apenas do tratamento T7. Para os demais tratamentos não houve diferença estatística.

\section{Coeficiente de uniformidade de Christiansen}

A Figura 5 apresenta os valores de CUC médio para os tratamentos em cada avaliação, e sua classificação, segundo Mantovani (2002). Observa-se heterogeneidade considerável nos valores iniciais de CUC, de maneira similar ao que ocorreu com os valores de CUD. Apenas os tratamentos T1, T2, T3, T5 e T6 mudaram de classificação.

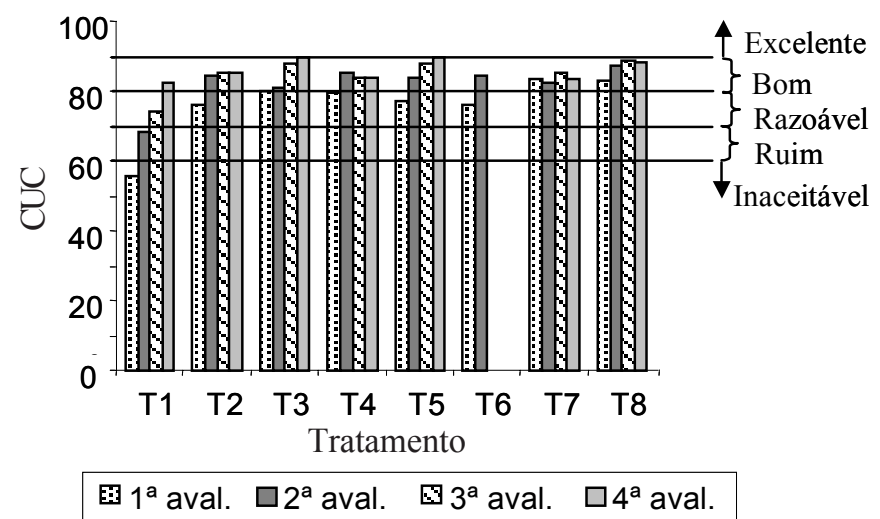

Figura 5. Valores de coeficiente de uniformidade de Christiansen (CUC) médio para os tratamentos e faixas de classificação, segundo Mantovani (2002)

No tratamento com ácido fosfórico a pH 2 (T1), a uniformidade se classifica como inaceitável na primeira avaliação, sendo classificada como bom na quarta avaliação. O tratamento com ácido fosfórico a pH 3 (T2) passou de razoável, na primeira avaliação, para bom na quarta.

Para os tratamentos com hipoclorito de sódio, os valores de CUC mantêm-se na faixa bom, em todas as avaliações, com exceção da concentração de $25 \mathrm{mg} \mathrm{L}^{-1}$ (T5), que na primeira avaliação se encontrava na faixa razoável, passando para bom nas outras avaliações.

No tratamento com impacto mecânico (T6), verificou-se ganho de uniformidade, passando da faixa razoável na primeira avaliação, para bom na segunda.

Os valores de CUC para os tratamentos com Reciclean (T7 e T8) não sofreram grande alteração, mantendo-se na faixa bom em todas as avaliações; entretanto, no tratamento com $25 \mathrm{mg}$ $\mathrm{L}^{-1}$ (T8), houve pequeno acréscimo na uniformidade.

A Tabela 3 apresenta os aumentos nos valores de CUC da primeira para a última avaliação, analisados pelo teste de Tukey, com $5 \%$ de probabilidade.

Tabela 3. Aumento nos valores de coeficiente de uniformidade de Christiansen (CUC) após aplicação dos tratamentos em relação aos valores iniciais

\begin{tabular}{cc}
\hline Tratamento & Aumento do CUC* \\
\hline T1 & $27,10 \mathrm{a}$ \\
T2 & $8,94 \mathrm{a} \mathrm{b}$ \\
T3 & $9,31 \mathrm{a} \mathrm{b}$ \\
T4 & $4,45 \mathrm{~b}$ \\
T5 & $12,91 \mathrm{a} \mathrm{b}$ \\
T6 & $8,06 \mathrm{a} \mathrm{b}$ \\
T7 & $-0,30 \mathrm{~b}$ \\
T8 & $5,36 \mathrm{~b}$ \\
\hline
\end{tabular}

* As médias seguidas por uma mesma letra não diferem estatisticamente pelo teste de Tukey, em nível de $5 \%$ de probabilidade

Como se observa, ocorreu diferença estatística apenas entre o tratamento com ácido fosfórico a pH 2,0 (T1) e os tratamentos com Reciclean (T7 e T8) e $50 \mathrm{mg} \mathrm{L}^{-1}$ de hipoclorito de sódio (T4), pelo teste de Tukey, com 5\% de probabilidade. Para os demais tratamentos não se observou diferença estatística.

\section{Análise de custo}

A Tabela 4 apresenta um comparativo dos custos dos tratamentos em relação ao aumento no CUD. O tratamento T1, embora superior no quesito aumento no CUD, possui custo muito elevado, inviabilizando seu uso em equipamentos instalados em lavouras de culturas de baixo a médio valor econômico. O tratamento T5, além de possuir a segunda maior posição no quesito citado, possui o menor custo, mostrandose o tratamento com a melhor relação benefício/custo, seguido pelos tratamentos T2, T3 e T6.

Tabela 4. Comparativo dos custos dos tratamentos em relação ao aumento no coeficiente de uniformidade de distribuição (CUD)

\begin{tabular}{ccc}
\hline Tratamento & Custo $\left(\mathrm{R} \$\right.$ ha $\left.^{-1}\right)$ & Aumento CUD \\
\hline T1 & 169,13 & 42,28 \\
T2 & 28,19 & 18,55 \\
T3 & 45,85 & 18,55 \\
T4 & 30,68 & 9,63 \\
T5 & 24,88 & 26,64 \\
T6 & 30,22 & 16,01 \\
T7 & 61,63 & $-0,64$ \\
T8 & 30,81 & 10,49 \\
\hline
\end{tabular}

Nos tratamentos de T3 a T5, observa-se que o custo maior se deve ao ácido fosfórico (Tabela 5); este custo poderia ser reduzido usando-se outro ácido, como o clorídrico ou o sulfúrico, que possuem um valor de mercado bem aquém do utilizado no experimento. Os custos de um quilograma dos ácidos clorídrico e sulfúrico são $\mathrm{R} \$ 1,38$ e R \$ 1,00, respectivamente, mas é preciso acrescentar que, para a compra desses dois produtos, é necessária uma autorização da Polícia Federal, devido à utilização desses produtos para a fabricação de 
drogas, segundo Resolução $N^{\circ} 147$ da Agência Nacional de Vigilância Sanitária, de 27 de maio de 1999. Esses preços foram consultados no dia 26 de agosto de 2002, junto ao fornecedor onde foram comprados os produtos utilizados no experimento, na cidade de Belo Horizonte, MG.

Tabela 5. Quantidades e custos dos produtos utilizados nos tratamentos T1, T2, T3, T4, T5, T7 e T8, para as condições experimentais

\begin{tabular}{lccrrrr}
\hline \multirow{2}{*}{ Descrição } & \multicolumn{2}{c}{ Conc. Preço $\mathrm{L}^{-1}$ Custo $\mathrm{m}^{-3}$} & & Aplic. & 3 Aplic. \\
& $\mathrm{L} \mathrm{m}^{-3}$ & \multicolumn{2}{c}{$\mathrm{R} \$$} & \multicolumn{3}{c}{$\mathrm{RS} \mathrm{ha}^{-1}$} \\
\hline T1 ácido & 1,20 & 9,72 & 11,66 & 77,80 & 169,13 \\
T2 ácido & 0,20 & 9,72 & 1,94 & & 12,97 & 28,19 \\
T3 hipoclorito & 1,22 & 0,60 & 0,73 & 4,88 & 10,61 & 45,85 \\
ácido & 0,25 & 9,72 & 2,43 & 18,64 & 35,24 & \\
T4 hipoclorito & 0,61 & 0,60 & 0,37 & 2,44 & 5,31 & 30,68 \\
ácido & 0,18 & 9,72 & 1,75 & 13,42 & 25,37 \\
T5 hipoclorito & 0,43 & 0,60 & 0,26 & 1,72 & 3,74 & 24,88 \\
ácido & 0,15 & 9,72 & 1,46 & 11,18 & 21,14 \\
T7 reciclean & 0,25 & $17,00^{*}$ & 4,25 & 28,35 & & 61,63 \\
T8 reciclean & 0,13 & $17,00^{*}$ & 2,13 & 14,17 & & 30,81 \\
\hline
\end{tabular}

* O valor deste produto acompanha o dólar americano. A conversão para o Real foi feita no dia 26 de agosto de 2002. O valor do Reciclean é US\$ 5,50 $\mathrm{L}^{-1}$

A análise de custos dos resultados é apresentada nas Tabelas 5 e 6. Para os tratamentos de T3 a T5, são mostrados os custos individualizados de hipoclorito e ácido fosfórico. $\mathrm{O}$ tratamento $\mathrm{T} 1$ foi o que se mostrou mais oneroso, seguido pelo tratamento T7. O tratamento T5 mostrou-se mais econômico que os demais, seguido pelo tratamento T2.

Tabela 6. Custo da mão-de-obra utilizada no tratamento T6 para as condições experimentais

\begin{tabular}{lccccc}
\hline Descrição & $\begin{array}{c}\text { Hora } \\
\text { Homem } \\
\mathrm{ha}^{-1}\end{array}$ & $\begin{array}{c}\text { Horas de } \\
\text { Trabalho } \\
\text { por Dia }\end{array}$ & $\begin{array}{c}\text { Custo por } \\
\text { Pessoa por } \\
\text { Mês (R\$) }\end{array}$ & \multicolumn{2}{c}{ Custo R\$ } \\
\hline $\begin{array}{l}\text { Impacto } \\
\text { mecânico }\end{array}$ & 14 & 7 & 302,22 & 15,11 & 30,22 \\
\hline
\end{tabular}

Como se observa, o tratamento T6 possui custo bem abaixo daquele dos outros tratamentos, cujos resultados foram similares para a limpeza dos emissores; entretanto, há de se evidenciar o fato de que não há aplicação de nenhum produto químico, o que seria necessário para a morte das ferrobactérias e algas; isto implica no fato de que, em curto prazo, o efeito seja satisfatório, mas o resíduo que fica na mangueira pode servir de inóculo para um novo desenvolvimento de colônias.

Uma boa alternativa seria associar este tratamento à utilização de um produto químico, como o cloro ou o ácido, o que só seria possível caso não fosse utilizado em cultivos orgânicos pois neste tipo de agricultura não é permitido o uso desses produtos.

\section{CONCLUSÕES}

1. O tratamento com ácido fosfórico em $\mathrm{pH} 2$ foi o que forneceu o melhor resultado, quando se avaliou a melhoria da uniformidade de irrigação do sistema, entretanto, possui custo elevado.

2. O tratamento com $25 \mathrm{mg} \mathrm{L}^{-1}$ de hipoclorito de sódio foi o que apresentou a melhor relação benefício/custo, sendo o mais econômico e o segundo melhor quanto a uniformidade de irrigação do sistema, o que o torna o mais indicado para limpeza de sistemas de irrigação por gotejamento.

3. O tratamento com impacto mecânico constitui uma alternativa para recuperação de sistemas de irrigação por gotejamento em geral, com destaque para sistemas de cultivos orgânicos.

4. O produto Reciclean não forneceu um resultado satisfatório nas três aplicações realizadas.

\section{AGRADECIMENTOS}

Ao Programa Nacional de Pesquisa e Desenvolvimento do Café, PNP\&D-Café/ EMBRAPA, pelo suporte financeiro; à Fazenda Vista Alegre e seus funcionários, pelo apoio ao desenvolvimento dos trabalhos.

\section{LITERATURA CITADA}

Agência Nacional de Vigilância Sanitária, Resolução $\mathrm{N}^{\circ} 147$ de 27 de maio de 1999. Lista D2. Lista de insumos químicos utilizados com precursores para fabricação e síntese de entorpecentes e/ou psicotrópicos. http:// www.saude.pr.gov.br/ftp/Legislacao_Vigilancia_Sanitaria/ Resolucao\%20147_99.doc (10 ago 2002).

ASAE. American Society of Agricultural Engineers. Standard engineering practices data: EP 458. Field evaluation of microirrigation systems. St. Joseph: ASAE 1996 p.792-797.

Bernardo, S. Manual de irrigação, 6 ed. Viçosa: Imprensa Universitária. 657p. : il. 1995.

Bucks, D.A.; Nakayama, F.S. Injection of fertilizer and other chemicals for drip irrigation. Proccedings Agri-Turf Irrigation Conference, Houston, Texas, Irrigation Association, Silver Spring, Maryland. 1980. p166-180.

Cordeiro, E.A. Influência do tratamento de água ferruginosa no desempenho de sistema de irrigação por gotejamento. Viçosa: UFV, 92p. 2002. Dissertação Mestrado.

Denículi, W.; Bernardo, S.; Thiébaut, J.T.L.; Sediyama, G.C. Uniformidade de distribuição de água, em condições de campo num sistema de irrigação por gotejamento. Revista Ceres, Viçosa, v.27, n.150, p155-162, 1980.

Keller, J.; Karmeli, D. Trickle irrigation design. California: Rain Bird Sprinkler Manufacturing Corporation, 1975. 133p.

Mantovani, E.C. AVALIA - Manual do usuário. Viçosa: DEA/ UFV -PNP\&D/Café/EMBRAPA. 2002. 100 p.

Martinko, J.; John, M.; Pack, J. Metabolic diversity. In: Brock, B.; Madigan, M.T.; Martinko, J.M.; Parker, J. Biology of microorganisms. 8. ed. Upper Saddle River, New Jersey: Prentice-Hall, 1997. 986p. Cap. 13.

Pitts, D.J. ; Haman, D.Z. ; Smajstrla, A.G. Causes and prevention of emitter plugging in microirrigation systems. Gainesville: Florida Cooperative Extension Service. University of Florida. 1990. 12p. Bulletin 258

Ravina, I.; Paz, E.; Sofer, Z.; Marcu, A.; Shisha, A.; Sagi, G. Control of emitter clogging in drip irrigation with reclaimed wastewater. Irrigation Science, New York, v.13, p.129-139. 1992. 